\title{
Phosphorus retention in a dammed reservoir in Ontario, Canada: Implications for nutrient management
}

N. $\mathrm{KAO}^{1 *}$, C.T. PARSONS ${ }^{2}$, A. NIEDERKORN ${ }^{1}$, M. MOHAMED $^{2}$, R.J. SORICHETTI ${ }^{3}$ AND P. VAN CAPPELLEN ${ }^{1}$

${ }^{1}$ Ecohydrology Research Group, University of Waterloo, Waterloo, Ontario, Canada (*correspondence: nady.kao@uwaterloo.ca)

${ }^{2}$ Environmet and Climate Change Canada, Burlington, Ontario, Canada

${ }^{3}$ Ontario Ministry of the Environment, Conservation and Parks, Etobicoke, Ontario, Canada

Harmful algal blooms in the western basin of Lake Erie (USA-Canada) have been increasing in frequency and severity since the late 1990s. Excess loads of phosphorus (P) from the lake's watershed are one of the primary drivers of this re-eutrophication. The Thames River, in southern Ontario, is the largest Canadian tributary source of $\mathrm{P}$ to Lake Erie's western basin. Yet, the role of dammed reservoirs on $\mathrm{P}$ loading and speciation in this river corridor remains poorly characterized. We estimated annual and seasonal retention efficiency (RE) of the following $P$ pools: dissolved reactive $P$ (DRP), dissolved unreactive P (DUP) and total P (TP) by the largest reservoir (Fanshawe) in the Thames River basin using a mass balance approach and two years of sampling data (2018-2019). Four load estimation models were used to quantify P loads into and out of the reservoir. Results show that, on an annual basis, the reservoir was a P sink (RE: 29 to $46 \%$ ) with a slight increase of the outflow DRP:TP ratios. However, loads, RE and DRP:TP showed systematic seasonal variations. For TP, retention was highest in winter and fall (RE: 49 to 69\%), while the reservoir acted as a net source during the summers and one spring season (RE: -25 to $110 \%$ ). Furthermore, the reservoir's outflow DRP fraction increased during the summers, ostensibly driven by inreservoir stratification and internal $\mathrm{P}$ loading. Our results show that Fanshawe Reservoir exerts a major influence on the flow and speciation of $\mathrm{P}$ on the Thames River and, thus, represents a potential point of intervention for $\mathrm{P}$ management. 